\title{
Experimental Induction of an Abnormal Ipsilateral Visual Field Representation in the Geniculocortical Pathway of Normally Pigmented Cats
}

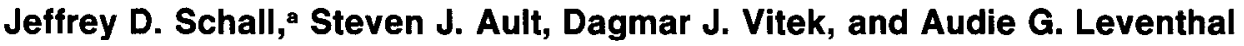 \\ Department of Anatomy, University of Utah School of Medicine, Salt Lake City, Utah 84132
}

In the normally pigmented neonatal cat, many ganglion cells in temporal retina project to the contralateral dorsal lateral geniculate nucleus (LGNd) and medial interlaminar nucleus (MIN). Most of these cells are eliminated during postnatal development. If one optic tract is sectioned at birth, much of this exuberant projection from the contralateral temporal retina is stabilized (Leventhal et al., 1988b). To determine how the abnormal projection from the contralateral temporal retina is accommodated in the central visual pathways, neuronal activity was recorded in the visual thalamus and cortex of adult cats whose optic tracts were sectioned as neonates.

The recordings showed that up to $20^{\circ}$ of the ipsilateral hemifield is represented in the LGNd and MIN. Recordings from areas 17 and 18 of the intact visual cortex showed that up to $20^{\circ}$ of the ipsilateral visual field is also represented and that the ipsilateral representation is organized as in a Boston Siamese cat (Hubel and Wiesel, 1971; Shatz, 1977; Cooper and Blasdel, 1980) or a heterozygous albino cat (Leventhal et al., 1985b). The extent of the ipsilateral visual field representation was greater in area 18 than in area 17; the extent of the ipsilateral hemifield representation in areas 17 and 18 varied with elevation, increasing with distance from the horizontal meridian. The receptive fields of cells in the LGNd and visual cortex subserving contralateral temporal retina were abnormally large. Otherwise, their receptive field properties seemed normal.

In the same animals studied physiologically, HRP was injected into the ipsilateral hemifield representation in the LGNd and MIN of the intact hemisphere. The topographic distribution of the $\alpha$ and $\beta$ cells, respectively, labeled by these injections correlated with the elevation-related changes in the ipsilateral visual field representation in areas 18 and 17.

Our results indicate that the retinotopic organization of the mature geniculocortical pathway reflects the abnormal pattern of central projections of ganglion cells in neonatally optic tract sectioned cats. Thus, if they do not die, retinal ganglion cells normally eliminated during development are

\footnotetext{
Received May 21, 1987; revised Oct. 14, 1987; accepted Oct. 20, 1987.

This investigation was supported by PHS Grant EY04951 to A.G.L., NRSA EY05863 to S.J.A., and NRSA EY05767 to D.J.V.

Correspondence should be addressed to Audie G. Leventhal at the above address.

a Present address: Department of Brain and Cognitive Science, E25-634, MI'I Cambridge, MA 02139.

Copyright (C) 1988 Society for Neuroscience $0270-6474 / 88 / 062039-10 \$ 02.00 / 0$
}

capable of making seemingly normal, functional connections. The finding that an albino-like representation of the ipsilateral hemifield can be induced in the visual cortex of normally pigmented cats suggests that the well-documented defects in the geniculocortical pathways of albinos are secondary to the initial misrouting of ganglion cells at the optic chiasm (Kliot and Shatz, 1985) and not a result of albinism per se.

The various forms of albinism result in abnormalities throughout the visual pathways (Guillery, 1969; Creel, 1971; Guillery and Kaas, 1971; Hubcl and Wicscl, 1971; Kaas and Guillcry, 1973; Shatz, 1977; Stone et al., 1978; Cooper and Pettigrew, 1979b; Cooper and Blasdel, 1980; Leventhal and Creel, 1985; Leventhal et al., 1985b). The abnormal ipsilateral visual field representation in the Siamese cat appears to result from a misrouting of the axons of many retinal ganglion cells in temporal retina at the optic chiasm early in development (Kliot and Shatz, 1985).

In the neonatal, normally pigmented cat there is an exuberant projection from the ganglion cells in temporal retina to the contralateral LGNd and MIN (Leventhal et al., 1988a). Most of these ganglion cells are eliminated through the course of normal development, but sectioning of one optic tract (OTX) in the neonate results in the survival of many of the contralaterally projecting ganglion cells in the temporal retina ipsilateral to the lesion (Leventhal et al., 1988a). To investigate the functional significance in the geniculocortical pathway of this stabilized exuberant projection, microelectrode recordings were made in the visual thalamus and cortex. Our results indicate that an albino-like abnormal representation of the ipsilateral visual field is established in the geniculocortical pathways consequent to the survival of significant numbers of contralaterally projecting cells in temporal retina of OTX cats.

\section{Materials and Methods}

Subjects. Single-unit activity was recorded in normally pigmented adult cats that had one OTX on postnatal day 1 as described in the accompanying paper (Leventhal et al., 1988a). Control data were available from animals used in previous investigations of normal (Leventhal, 1983; Schall et al., 1986) and hypopigmented (Leventhal and Creel, 1985; Leventhal et al., 1985b) cats. The animals included in this study were also studied anatomically; the results are presented in the accompanying papers (Leventhal et al., 1988a, b).

Physiological recording procedures, receptive field mapping, electrode tract reconstruction, HRP injections, and histochemistry. All of these procedures have been described in detail elsewhere (Leventhal and Creel, 1985; Schall et al., 1986). 

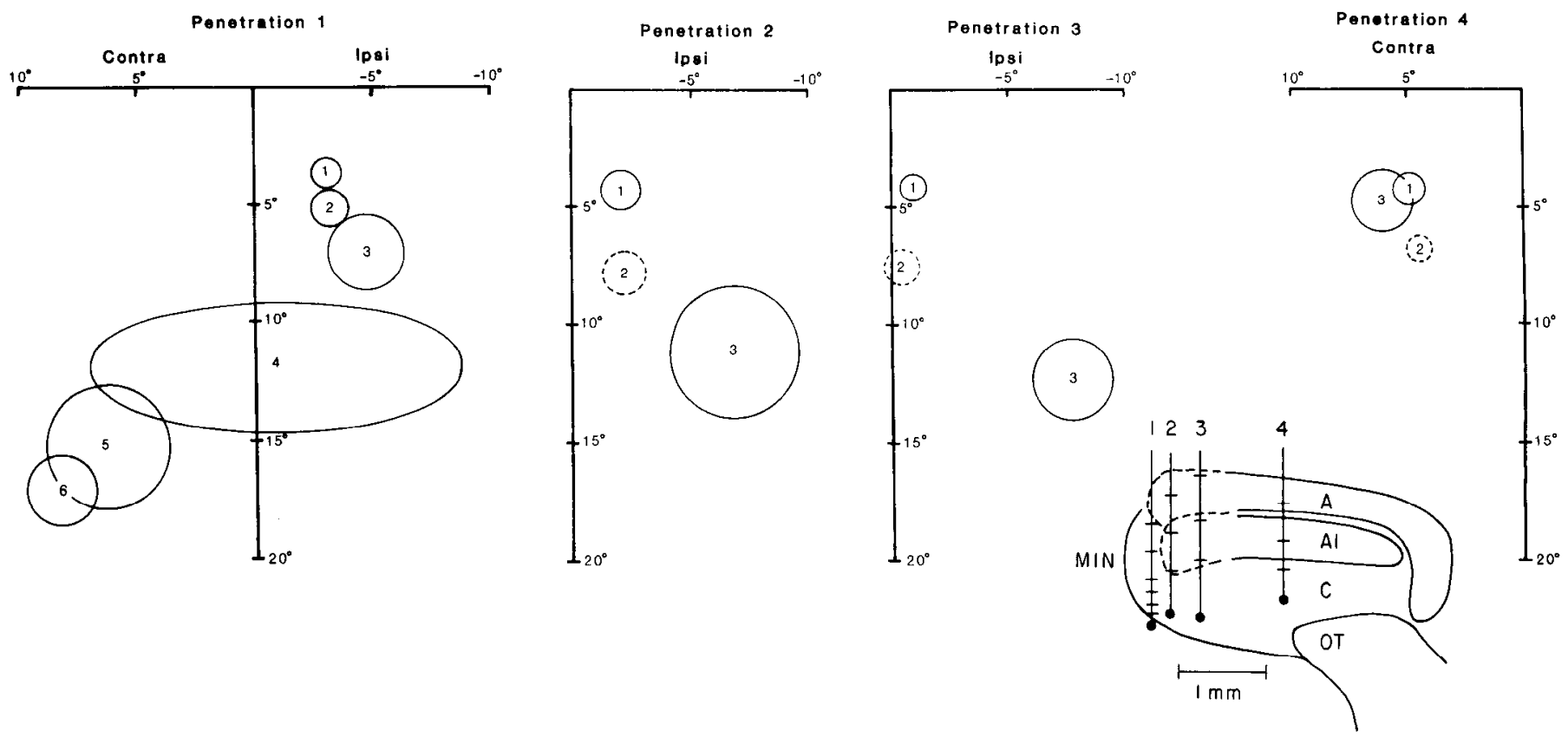

Figure 1. Receptive fields of cells encountered in penetrations into the LGNd and MIN of an adult cat whose left optic tract was sectioned neonatally. The contralateral hemifield is represented on the left; the ipsilateral hemifield, right. The positions of the units in each penetration are indicated in the coronal section by the horizontal lines and are numbered dorsal to ventral. Cells subserving the ipsilateral hemifield had receptive fields $4^{\circ}-15^{\circ}$ into superior retina. The laminar borders drawn with dashed lines were somewhat uncertain due to the presence of HRP reaction product (Fig. 2). Receptive fields mapped through the contralateral eye are drawn with solid lines, and receptive fields mapped through the ipsilateral eye are drawn with dashed lines. In this animal, at least $10^{\circ}$ of the ipsilateral hemifield was represented in the LGNd and MIN. In this cat, HRP was injected into the region of the LGNd representing the ipsilateral hemifield. The results are illustrated in Figure 2.

\section{Results}

We recorded over 250 single units in the LGNd, MIN, and visual cortical areas 17 and 18 of adult, normally pigmented OTX cats. A quantitative analysis of the distribution of ipsilaterally and contralaterally projecting cells in the retinae of these animals is presented in the accompanying paper (Leventhal et al., 1988a).

\section{Evidence for an ipsilateral visual field representation in the $L G N d$}

Unlike in the LGNd of Siamese cats (Guillery and Kaas, 1971), there were no obvious cellular discontinuities in lamina A1 of OTX cats. Neuronal activity was recorded in the right LGNd and MIN of normally pigmented cats whose left optic tract was sectioned on postnatal day 1 . The receptive fields of LGNd and MIN cells encountered in 4 penetrations in the same coronal plane in one cat are illustrated in Figure 1. Penetration 4 was the most lateral, and the receptive fields recorded in laminae $\mathrm{A}, \mathrm{Al}$, and $\mathrm{C}$ were all located in the contralateral hemifield. Penetrations 2 and 3 passed through the medial aspect of the LGNd. The receptive fields encountered dorsally were close to the vertical meridian. More specifically, the receptive fields of unit 1 in penetration 2 and unit 1 in penetration 3 appear to have been $1^{\circ}-2^{\circ}$ into ipsilateral hemifield. However, given the $1^{\circ}-2^{\circ}$ error in localizing the area centralis projection, we hesitate to conclude that these fields were, in fact, in the ipsilateral hemifield. The receptive fields encountered ventrally in the A laminae in these 2 penetrations extended $10^{\circ}$ into the ipsilateral visual field; these units were $Y$ cells, and the azimuths, but not elevations, of their receptive fields were out of register with the receptive fields of the cells recorded immediately above them.
This penetration was typical; we never found a significant amount of the ipsilateral hemifield represented in the dorsal parts of the $\Lambda$ laminae. However, in a number of penctrations the receptive fields of Y cells in the bottom of laminae Al, just above laminae $\mathrm{C}$, extended $10^{\circ}$ or more into the ipsilateral hemifield. Finally, penetration 1 passed through the MIN; the receptive fields drifted from $10^{\circ}$ in the ipsilateral hemifield dorsally to $10^{\circ}$ in the contralateral hemifield ventrally. The receptive fields were very large, and some spanned the midline (Fig. 1). All MIN cells studied were $Y$ cells.

Following the microelectrode recordings in this cat, HRP was electrophoretically injected into the ipsilateral visual field representation; the resulting injection site included the laminated portion of both the LGNd and the MIN. The $\alpha$ cells labeled by the injection extended over $17^{\circ}$ (about $4 \mathrm{~mm}$ ) from the vertical meridian in the contralateral temporal retina at elevations $4^{\circ}-$ $8^{\circ}(1-2 \mathrm{~mm})$ above the horizontal meridian. ${ }^{1}$ The distribution

\footnotetext{
${ }^{1}$ Recent evidence (Leventhal et al., 1985b) indicates that "normally" pigmented cats carrying the recessive allele for tyrosinase-negative albinism have an abnormally large number of contralaterally projecting $\alpha$ and $\beta$ cells in temporal retina. These animals also exhibit an abnormal representation of the ipsilateral hemifield in visual cortex. Siamese cats are a form of tyrosinase-positive albino (Guillery, 1986, for review); the recessive allele for the Siamese abnormality is very common in the "normal" cat population. Thus, it is unclear the extent to which the ipsilateral field representation in the thalamus of "normally" pigmented cats (Kinston et al., 1969; Sanderson, 1971; Lee et al., 1984) is due to heterozygote effects; comparisons between the present results and those obtained previously must be made cautiously. A detailed electrophysiological study of the visual thalamus in known homozygous normal, OTX, heterozygote, Siamese, and albino cats is required to determine the precise manner in which the visual field is represented in OTX and hypopigmented animals.

All animals included in the present study were raised in our well-established breeding colony; all cats in the colony are homozygous and normally pigmented. The normally pigmented adult cats we have studied from our colony do not have
} 
of labeled $\alpha$ cells in this cat is shown in Figure 2. Contralaterally projecting $\beta, \mathrm{g} 1$, and $\mathrm{g} 2$ cells in temporal retina were also labeled by this injection, as is typical in OTX cats (Leventhal et al., 1988a). The cells stained most heavily as a result of this injection were concentrated in parts of the contralateral temporal retina in retinotopic correspondence with the receptive fields of the cells recorded (penetrations 1-3) at the injection site. Thus, direct retinal input to the $\mathrm{LGNd}$ could account for the ipsilateral hemifield representation in the thalamus of this animal.

\section{Organization of ipsilateral visual field representation in the visual cortex}

The ipsilateral visual field representation in the visual cortex was investigated in detail in neonatally optic tract sectioned cats; 29 penetrations into areas 17 and 18 yielded 193 single cells. All of the receptive fields in the ipsilateral hemifield considered in this report were activated through the cyc ipsilatcral to the optic tract lesion, contralateral to the hemisphere from which the recordings were obtained. The receptive fields mapped through the eye contralateral to the lesion, ipsilateral to the intact hemisphere, were all located in the contralateral hemifield. This result is to be expected since the ipsilateral nasal projection following neonatal optic tract section is not substantial (Jacobs et al., 1984; Leventhal et al., 1988a).

Figure 3 shows the receptive fields of cells encountered in 5 electrode penetrations at the same coronal level into the right hemisphere of a cat whose left optic tract was interrupted neonatally. The receptive fields of cells encountered in the most medial and in the most lateral penetrations represented the contralateral visual field. As the penetrations crossed the border between areas 17 and 18 , however, the receptive fields drifted into the ipsilateral visual field. The neurons representing the ipsilateral hemifield appeared to be normally orientation, direction, and velocity selective, and the transition from area 17 to area 18 was reflected in characteristic changes in receptive field size, velocity selectivity, and responsiveness (Orban et al., 1980). The retinal projections in this animal were abnormal and typical of what is observed in OTX cats. The anatomical results for this animal are included in the accompanying paper (Leventhal et al., 1988a).

In Figure 4 are shown the receptive fields of 5 electrode penetrations into the right hemisphere of a second cat whose left optic tract was sectioned neonatally. A systematic representation of the ipsilateral visual field is once again evident as penetrations 1-3 span the border between areas 17 and 18. Penetrations 2,4 , and 5 in this cat passed through the border between areas 17 and 18 at different coronal levels; in each case the ipsilateral visual field was represented.

Comparing the receptive fields observed in penetrations into areas 17 and 18, differences in the degree of ipsilateral representation are evident. Penetration 5 in Figure 4 passed through area 17 and encountered units with receptive fields up to $7^{\circ}$ in the ipsilateral hemifield. Penetrations 4 and 5 in Figure 5 passed through area 18 at approximately the same coronal level as penetration 5 in Figure 3. The receptive fields encountered in area 18 extended up to $15^{\circ}$ into the ipsilateral visual field. Thus,

significant numbers of contralaterally projecting $\alpha$ and $\beta$ cells more than 1 and $0.4 \mathrm{~mm}$, respectively, into temporal retina at elevations close to the horizontal meridian. In agreement with Illing and Wässle (1981), we find that, in normal animals, the width of the region of masotemporal overlap is smallest at the central area (horizontal meridian) and increases somewhat at peripheral elevations (see Leventhal et al., 1988a).
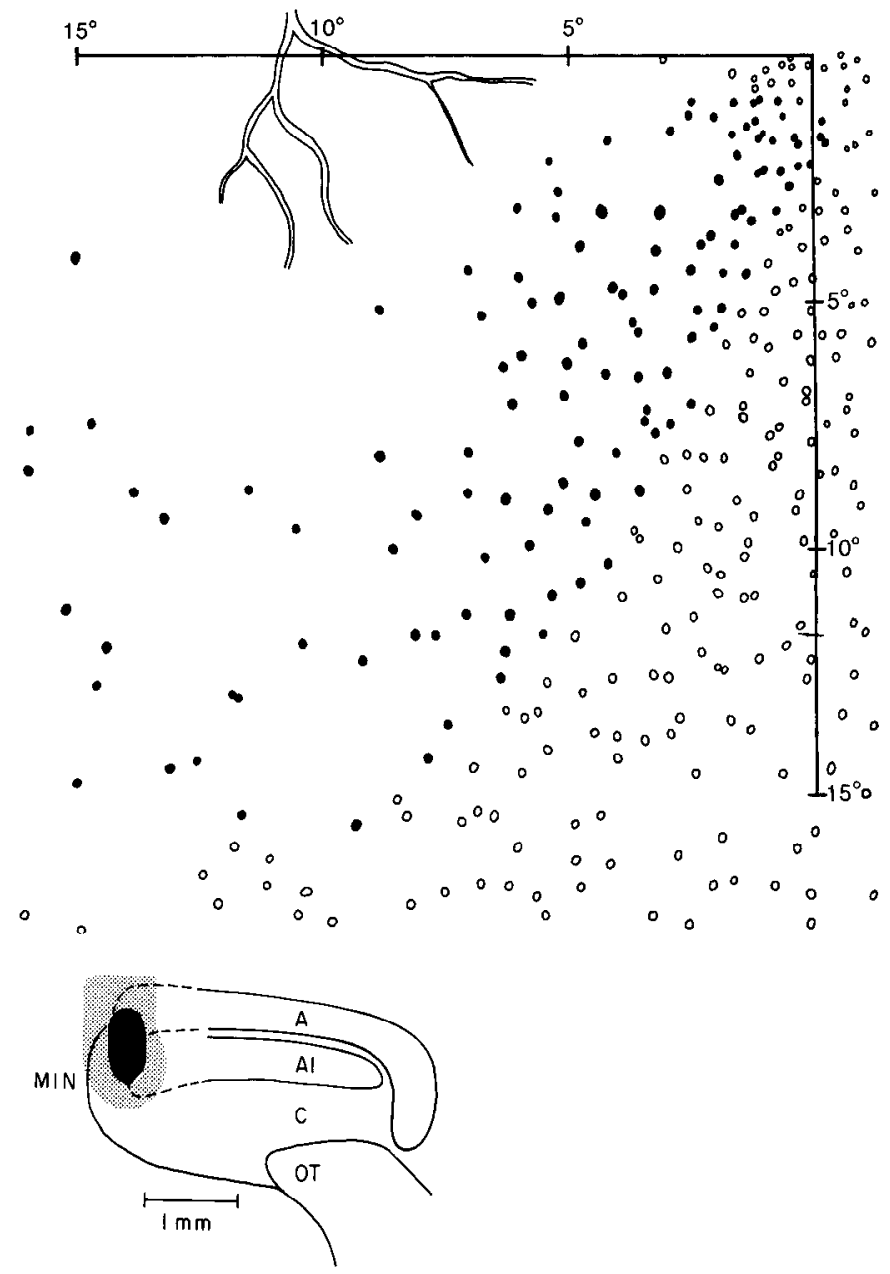

Figure 2. $\alpha$ Cells in the contralateral temporal retina labeled by an injection of HRP into the ipsilateral hemifield representation in the LGNd of a cat studied physiologically. Some of the recordings from this cat are illustrated in Figure 1. The contralateral superior temporal quadrant of the retina is shown. The injection site is indicated by the shading in the coronal section. $\alpha$ Cells with dendrites filled up to the third order are indicated by solid spots; less well filled cells, open spots. Notice that the $\alpha$ cells most heavily stained by the injection into the ipsilateral hemifield representation are located in the superior contralateral temporal retina at positions in retinotopic correspondence with the units recorded at the injection sites. Unlike the normal cat (Cooper and Pettigrew, 1979; Illing and Wässle, 1981; Leventhal et al., 1988a), many labeled $\alpha$ cells were found as far as $17^{\circ}$ (about $4 \mathrm{~mm}$ ) from the vertical meridian in the temporal retina contralateral to the injection. There were a few lightly labeled cells along the horizontal meridian in this cat. The absence of labeled cells there reflects the fact that our injection was small and located in the anterior portion of the LGNd, where the superior retina is represented. We do not know, therefore, how far into temporal retina along the horizontal meridian contralaterally projecting $\alpha$ cells actually extended in this animal.

a larger ipsilateral visual field representation is established in area 18 than in area 17 of OTX cats. As is typical of OTX cats, this cat had an abnormally large number of contralaterally projecting cells in temporal retina; $\alpha$ cells extended further than $\beta$ cells into the contralateral temporal retina. The anatomical results for this animal are included in the accompanying paper (Leventhal et al., 1988a).

Comparing the receptive fields encountered in penetrations at different coronal levels, it is evident that the maximum ipsilateral azimuth represented varies with elevation from the 
Figure 3. Receptive fields of cells encountered in penetrations into areas 17 and 18 of a normally pigmented, adult cat whose left optic tract was sectioned neonatally. At the conclusion of the recordings, this animal received HRP injections into the LGNd. A quantitative description of the anatomical results obtained in this cat are presented in Figures 8 and 11 of the accompanying paper (Leventhal et al., 1988a). In this figure, the contralateral hemifield is represented on the left; the ipsilateral hemifield, right. The positions of the electrode penetrations are indicated on a surface view of the brain and in the drawing of a coronal section; the arrowhead denotes the border between areas 17 and 18. The scale bar in the coronal section measures $1 \mathrm{~mm}$. The depth of each single unit is indicated by the short horizontal lines; the depth at which each penctration was concluded is indicated by the long horizontal line, with the value written at the side. Note that in this cat, as in Boston Siamese cats, there is a systematic representation of part of the ipsilateral hemifield at the border of areas 17 and 18.
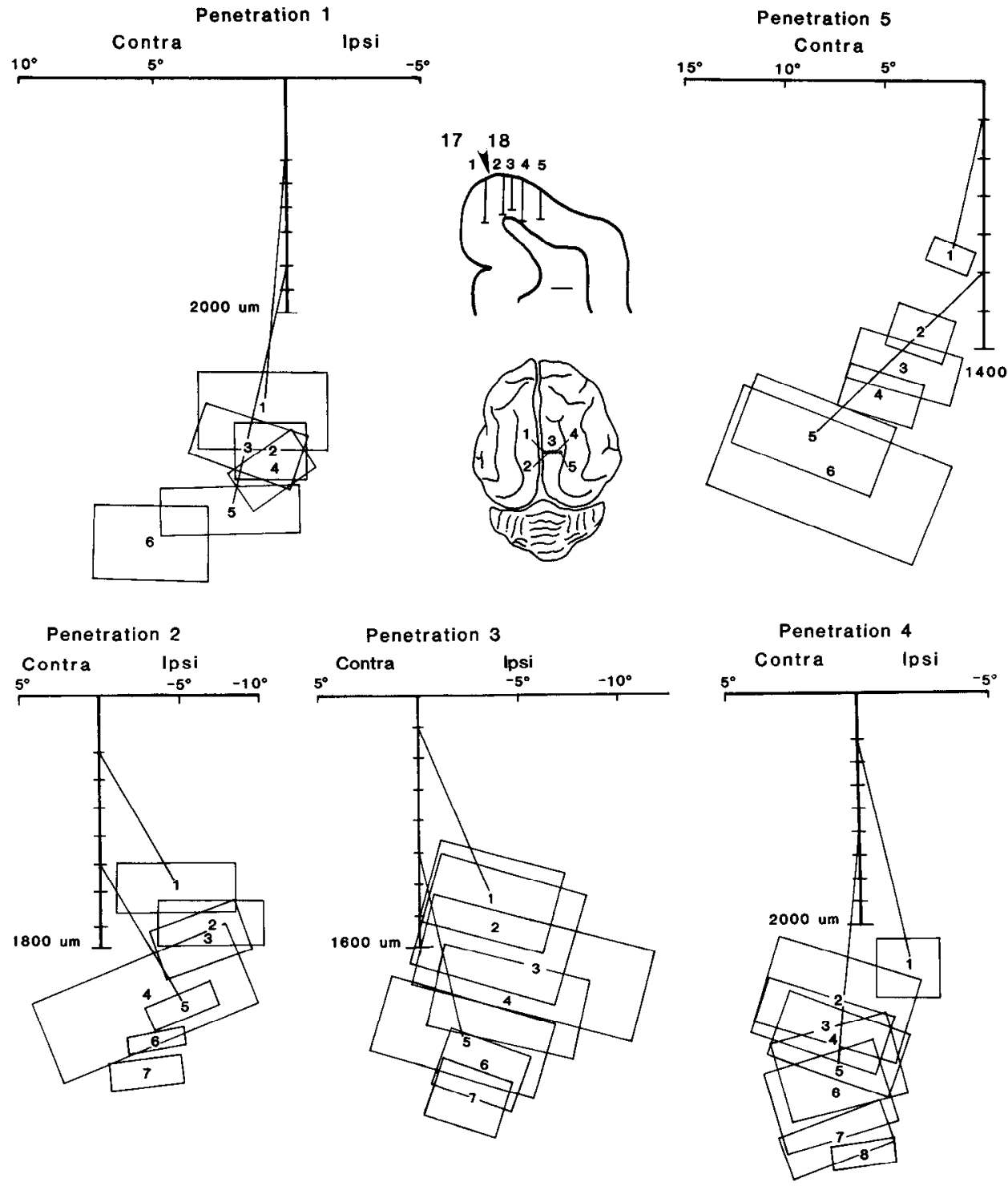

horizontal meridian. In Figure 5 are shown the receptive fields of 5 electrode penetrations into the right hemisphere of a third cat whose left optic tract was sectioned neonatally. Besides the systematic representation of the ipsilateral hemifield across the border between areas 17 and 18, a difference in the extent of ipsilateral representation with coronal level is evident. Penetrations 4 and 5 were rostral to penetrations 2 and 3 . The rostral penetrations encountered units subserving the lower visual field with an ipsilateral excursion up to $15^{\circ}$. The caudal penetrations encountered units subserving regions near the horizontal meridian with a maximum ipsilateral azimuth of $8^{\circ}$. Also, penetration 2 was rostral to penetration 4 in Figure 3, and the receptive fields of cells encountered in the more rostral penetration extended further into the ipsilateral hemifield than those encountered in the caudal penetration. The anatomical results for this animal are also presented in the accompanying paper (Leventhal et al., 1988a).

In all animals in which we observed an elevation-dependent difference in the amount of the ipsilateral hemifield represented, we also observed elevation-related differences in the distribution of contralaterally projecting cells in temporal retina. In all cases the ipsilateral hemifield representation reflected the spatial distribution of contralaterally projecting ganglion cells in temporal retina. This is shown for one cat in Figure 6. In this animal, many contralaterally projecting $\alpha$ cells located near the horizontal meridian extended up to $8^{\circ}$ (about $2 \mathrm{~mm}$ ) into temporal retina. Superior to the horizontal meridian, numerous contralaterally projecting $\alpha$ cells were found up to $17^{\circ}$ (about $4 \mathrm{~mm}$ ) into temporal retina. Superimposing the receptive fields of cells recorded in area 18 of this cat upon the retina using retinal landmarks as a guide (Fig. 6) clearly demonstrates that the ipsilateral hemifield representation in visual cortex follows the distribution of misprojecting ganglion cells. In the other cats in which both cortical topography and retinal projections were studied, the maximum ipsilateral azimuth of the cortical receptive fields in areas 17 and 18 was also consistent with the temporal excursion of the contralaterally projecting $\beta$ and $\alpha$ cells, respectively, at corresponding elevations.

The change in receptive field size with azimuth for cells in area 18 is illustrated in Figure $7 \mathrm{~A}$. All of the receptive fields were about $10^{\circ}$ below the horizontal meridian. In neonatally optic tract lesioned animals, receptive fields became significantly 

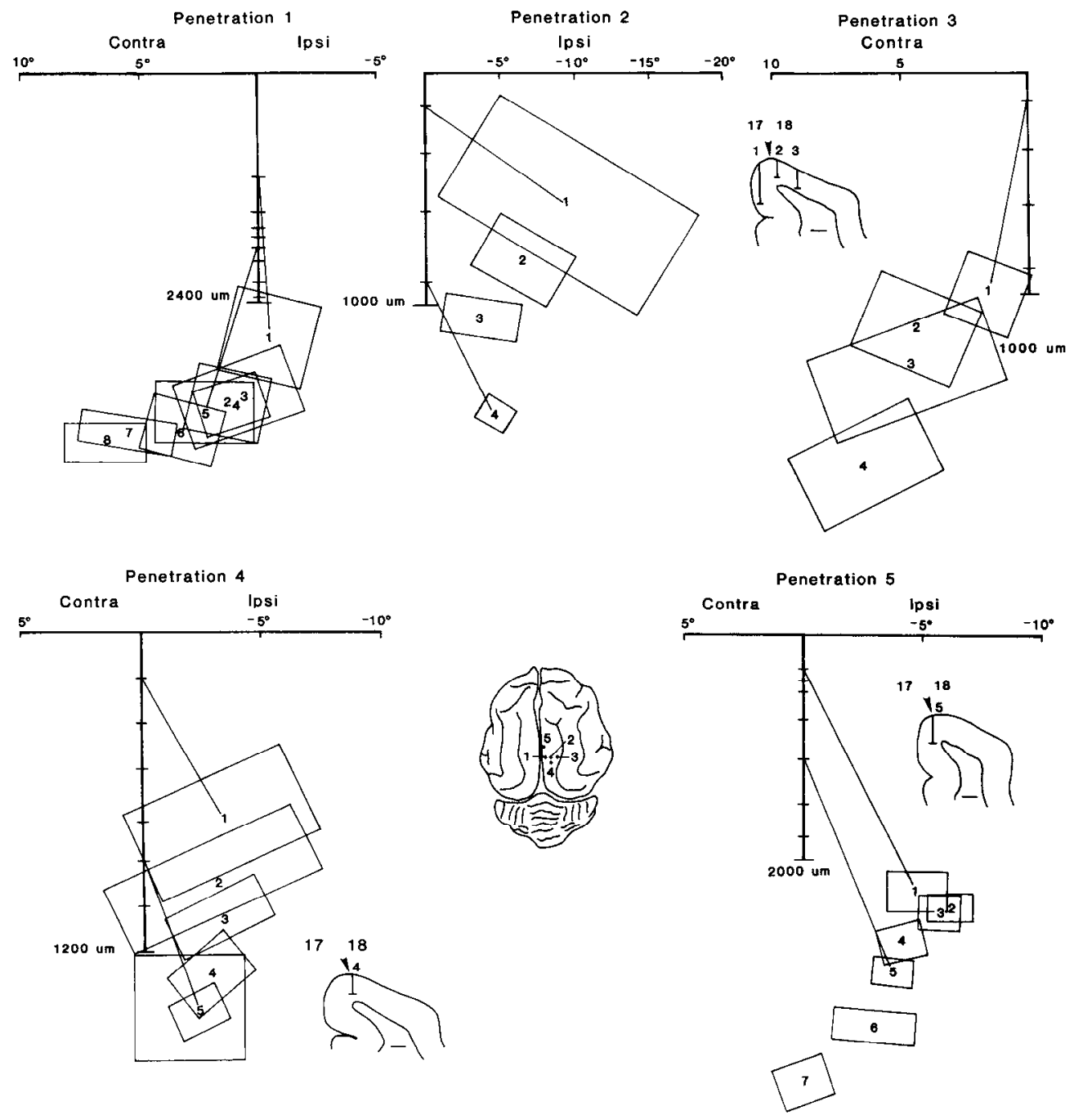

Figure 4. Receptive fields of cells encountered along penetrations in the visual cortex of a second neonatally optic tract sectioned cat. The retinal projections in this animal were also studied anatomically. The results from this animal are included in Figures 5, 8, and 11 of the accompanying paper (Leventhal et al., 1988a). The conventions are as explained in Figure 3. In this cat, penetrations 1-3 were at the same coronal level. The Boston Siamese pattern of ipsilateral visual field representation is evident. Penetrations 2,4 , and 5 followed the border between areas 17 and 18 ; the ipsilateral visual field representation is evident in each penetration.

larger than normal very rapidly as they moved into the ipsilateral hemifield. This increase in receptive field size was paralleled by a rapid decrease in the number of $\alpha$ cells ultimately providing their inputs as shown in Figure $7 B$.

In areas 17 and 18 the receptive fields of the cells subserving the most peripheral parts of the ipsilateral hemifield often contained "hot spots." That is, visual stimulation using small stimuli elicited better responses in some parts of the receptive field than in others. The greatest responses were usually obtained from the parts of the receptive field closest to the vertical meridian. When the receptive fields of the cortical cells studied were superimposed on the retina, these "hot spots" invariably corresponded to the regions "covered" by the greatest density of retinal ganglion cell dendrites.

\section{Discussion}

This investigation has demonstrated the experimental induction of an ipsilateral visual field representation in the geniculocortical pathway of normally pigmented, neonatally optic tract sectioned cats. The ipsilateral hemifield representation in the visual cortex was greater than the normal nasotemporal overlap (Hubel and Wiesel, 1965; Tusa et al., 1979) and was systematically organized like that of a Boston Siamese cat (Hubel and Wiesel, 1971; Shatz, 1977; Cooper and Blasdel, 1980) or an albino hetero- zygote cat (Leventhal et al., 1985b). The extent of the ipsilateral visual field representation was greater in area 18 than in area 17 and increased in regions away from the horizontal meridian. The abnormal representation of the ipsilateral visual field in the visual thalamus and cortex could be accounted for by the abnormal distribution of contralaterally projecting ganglion cells in the temporal retinae of the same animals.

\section{Organization of the ipsilateral visual field representation in the geniculocortical pathway}

In this study we investigated the organization of the ipsilateral visual field representation in the LGNd and MIN of OTX cats. Electrophoretic HRP injections were made following the microelectrode recordings in order to determine the retinal distribution of ganglion cells projecting to the regions studied electrophysiologically. Injections into regions of the LGNd and MIN representing the ipsilateral hemifield labeled cells in retinotopically appropriate regions of the contralateral temporal retina. We did not inject radioactive amino acids into one eye of the same animals, thus, we are unable to localize laminar boundaries definitively. Also, in the present study we chose to emphasize the organization of visual cortex and thus we did not study the organization of the LGNd of OTX cats in enough detail to define its retinotopic organization completely. Nevertheless, given our 


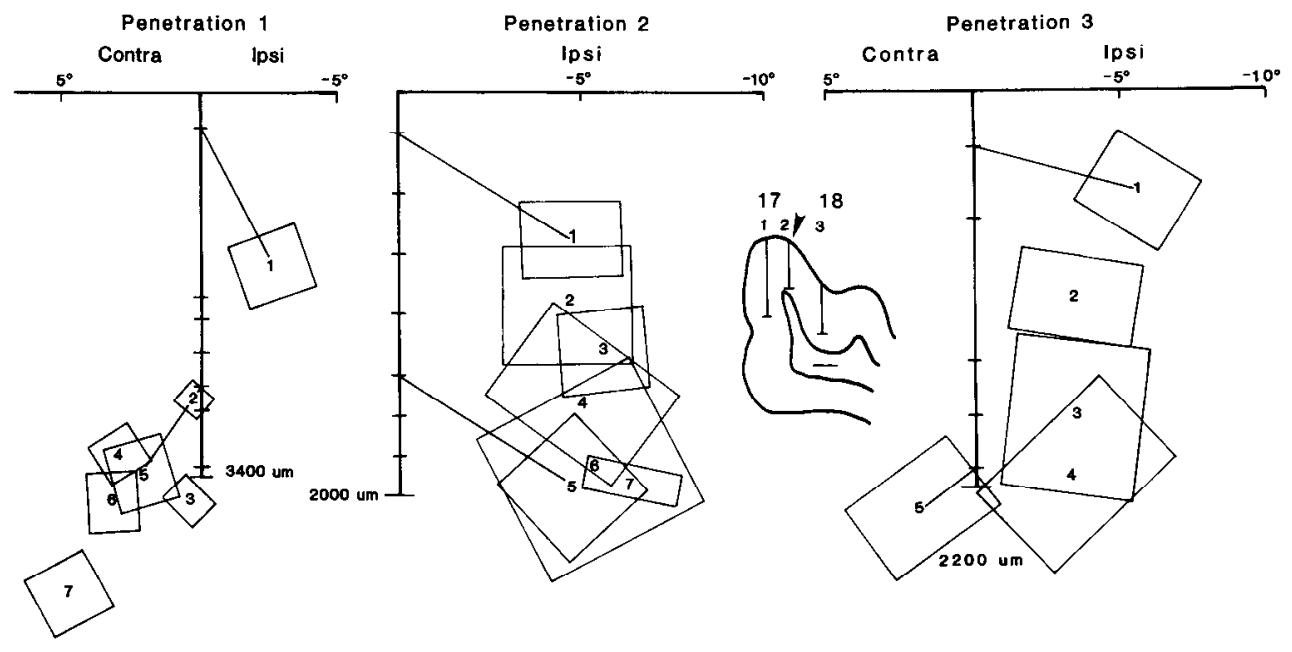

Figure 5. Receptive fields of cells encountered in penetrations into the right visual cortex of a third neonatally optic tract sectioned cat. The retinal projections in this animal were also studied anatomically. The results for this cat are included in Figures 6, 8, 9, and 11 of the accompanying paper (Leventhal et al., 1988a). A photomicrograph of the contralaterally projecting cells in the temporal retina of this cat is shown in Figure 4 of Leventhal et al. (1988a). The conventions are as in Figure 3. Penetrations 4 and 5 encountered cells that subserved the lower visual field; the maximum ipsilateral azimuth was $15^{\circ}$. Penetrations $1-3$ encountered cells that subserved elevations close to the horizontal meridian; the maximum ipsilateral azimuth was $8^{\circ}$.
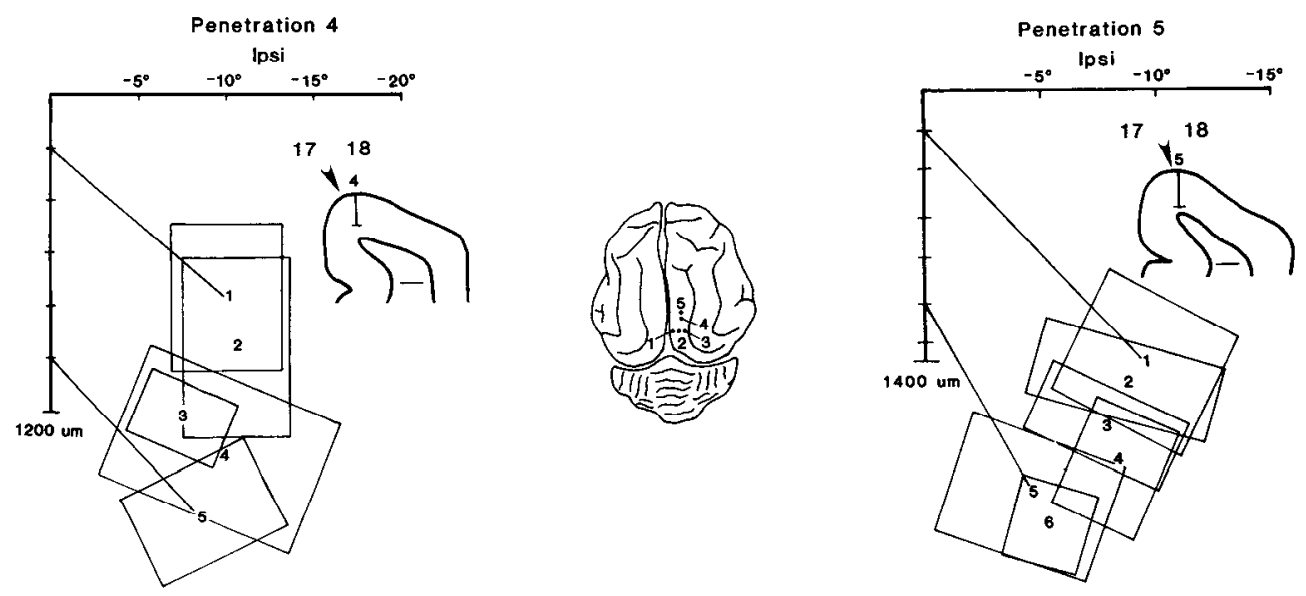

results, we feel that it is reasonable to conclude that the LGNd contains a sizable representation of the ipsilateral visual field in OTX cats; the cells with receptive fields furthest into the ipsilateral hemifield are $Y$ cells in the lateral portion of the MIN, probably lamina 3 (Guillery et al., 1980; Lee et al., 1984), as well as in the medial portion of lamina Al, close to the border with lamina C (Guillery, 1969).

There is currently no evidence at all for a sizable representation of the ipsilateral hemifield in lamina A1 of normal animals similar to the one observed in OTX cats. The retinotopic organization of the lamina A1 in OTX cats can, thus, be considered abnormal. On the other hand, in normal cats, most of the receptive fields in layer 3 of the MIN subserve the ipsilateral hemifield (Lee et al., 1984). Receptive fields of cells in layer 3 extend up to $30^{\circ}$ into the ipsilateral hemifield at elevations close to the horizontal meridian (see figs. 10 and 11 in Lee et al., 1984; see also Kinston et al., 1969; Sanderson, 1971). We did not study the MIN in enough detail to determine whether the ipsilateral hemifield representation is abnormal in OTX cats. ${ }^{2}$

\footnotetext{
${ }^{2}$ In normal cats, significant numbers of cells projecting contralaterally to the thalamus do not extend more than $1 \mathrm{~mm}$ into temporal retina (Cooper and Pettigrew, 1979a; Illing and Wässle, 1981) at elevations close to the horizontal meridian. Thus, direct retinal input can only account for $4^{\circ}-5^{\circ}$ of the normal ipsilateral hemifield representation in layer 3 of the MIN of normal cats. Conceivably, the bulk of the ipsilateral hemifield representation in lamina 3 of the MIN in normal animals arises indirectly via inputs from the lateral suprasylvian visual areas. These areas normally contain a substantial representation of the ipsilateral hemifield (Dow and Dubner, 1969; Spear and Baumann, 1975; Palmer et al., 1978);
}

In normal cats, $\alpha$ cells provide the major input to the MIN, and $\alpha$ and $\beta$ cells provide the only input to the A laminae (Leventhal, 1982; Rowe and Dreher, 1982; Sur and Sherman, 1982; Bowling and Michael, 1984; Leventhal et al., 1985a). Within the A laminae $\alpha$ cells ( $\mathrm{Y}$ cells) tend to terminate more ventrally than $\beta$ cells (X cells) (Mitzdorf and Singer, 1977; Bowling and Michael, 1984). In view of the normal distribution of $X$ and $Y$ cells afferents to the $L G N d$, the present results indicate that, in the different parts of the lateral geniculate nuclear complex in OTX cats, the extent of the ipsilateral representation reflects the extent of the contralateral temporal projection from the specific ganglion cell type providing the major input. We find that, in OTX cats, contralaterally projecting $\alpha$ cells extend further into temporal retina than do contralaterally projecting $\beta$ cells; the MIN and ventral portion of lamina $\mathrm{Al}$, the regions

connections between the MIN and these cortical areas have been well documented (Wilson and Cragg, 1967; Heath and Jones, 1972; Maciewicz, 1974; Palmer et al., 1978; Leventhal et al., 1980; Niimi et al., 1981; Tong et al., 1982; Raczkowski and Rosenquist, 1983). The superior colliculus, which also normally contains a sizable representation of the ipsilateral hemifield, has been reported to project only to the parvocellular C laminae in normal cats (Torrealba et al., 1981; Stein et al., 1985). Thus, at present there is no basis to suggest that tectal afferents are directly involved.

In neonatally O'TX cats, on the other hand, numerous contralaterally projecting $\alpha$ cells extend over $4 \mathrm{~mm}$ (Leventhal et al., 1988a) into temporal retina at elevations more than a millimeter from the horizontal meridian. We have shown that these cells project directly to the parts of the LGNd representing the ipsilateral hemifield (Figs. 1,2). Hence, direct retinal input can account for the bulk of the ipsilateral hemifield representation in the MIN of the OTX cat but not in the normal cat. 


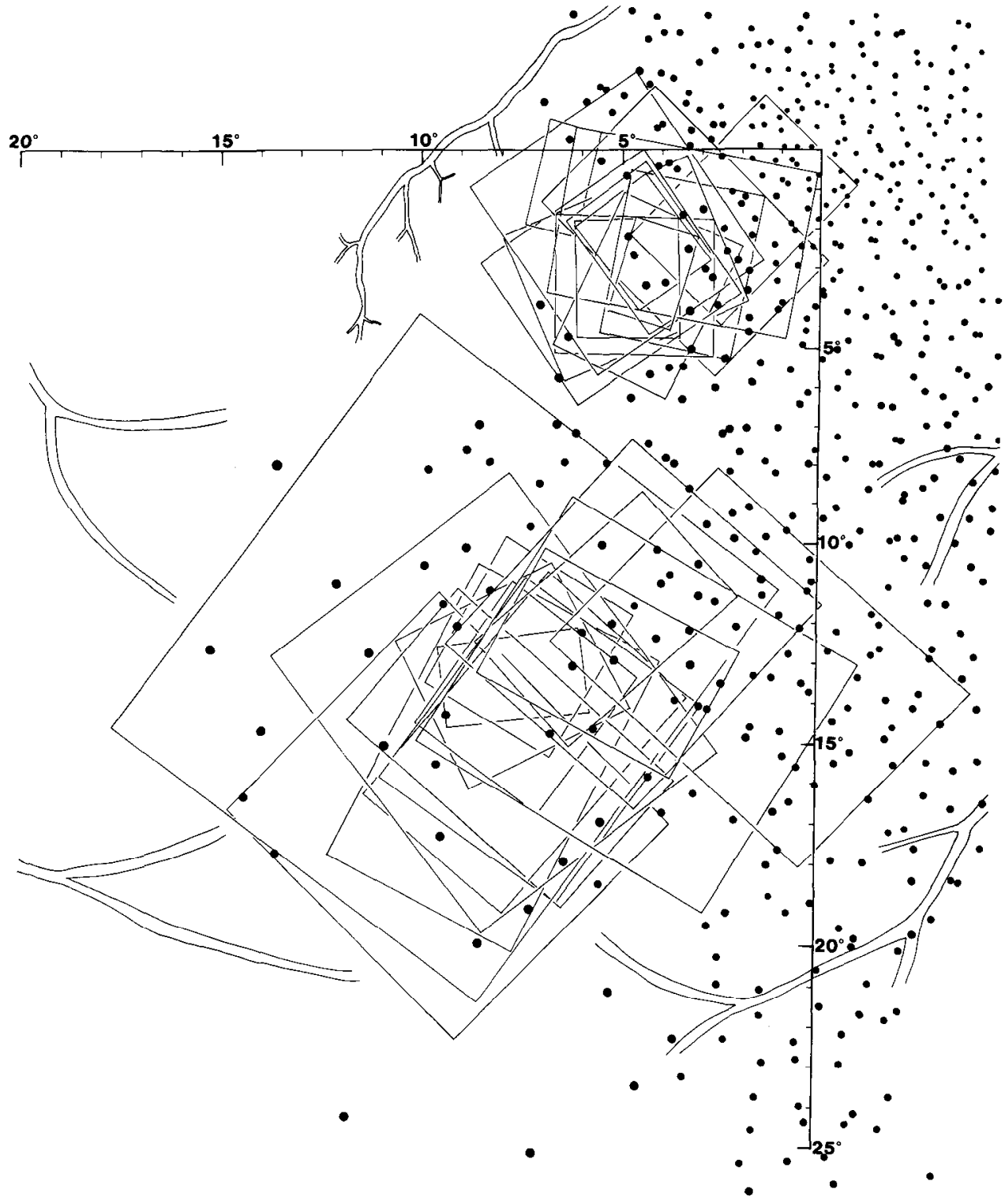

Figure 6. Receptive fields of cells in area 18 and $\alpha$ ganglion cells subserving the ipsilateral visual field in the same neonatally optic tract lesioned cat. The cell bodies of all of the $\alpha$ cells in temporal retina filled with HRP as a result of an injection of HRP into the contralateral LGNd and MIN are drawn. The horizontal and vertical meridians are illustrated. The receptive fields of all of the cells recorded in area 18 have been superimposed on the retinal coordinates based upon their visual field positions relative to retinal landmarks. Near the horizontal meridian contralaterally projecting $\alpha$ cells extend up to $6^{\circ}$ into temporal retina. In the region $10^{\circ}-20^{\circ}$ superior to the horizontal meridian contralaterally projecting $\alpha$ cells extend up to $15^{\circ}$ into temporal retina. Note that the representation of the ipsilateral visual field follows the distribution of misprojecting $\alpha$ cells. that normally receive the heaviest $Y$ cell inputs, contain the largest representation of the ipsilateral hemifield.

The present results also indicate that more of the ipsilateral hemifield is represented in area 18 than in area 17 of cats in which the optic tract was sectioned neonatally. The major thalamic input to area 18 is provided by $Y$ cells, and the major thalamic input to area 17 is provided by $X$ cells (Stone and Dreher, 1973; Singer et al., 1975; Tretter et al., 1975; Dreher et al., 1980). Hence, the large ipsilateral hemifield representation established in the LGNd and MIN by the contralaterally projecting $\alpha$ cells in temporal retina seems to be preserved in area $18 .^{3}$ The smaller ipsilateral hemifield representation established in the LGNd by the contralaterally projecting $\beta$ cells in temporal retina is preserved in area 17 . A similar difference in the ipsilateral hemifield representation in areas 17 and 18 exists in albino cats (Leventhal and Creel, 1985). Our interpretation of the present results is illustrated schematically in Figure 8.

${ }^{3}$ The ipsilateral hemifield representation cannot originate via the corpus callosum in OTX cats since neonatal, unilateral optic tract section deprives the hemisphere contralateral to the recordings of retinal inputs.

\section{Mechanisms mediating cell death in mammalian retina}

During the normal development of cat retina there is a period of naturally occurring cell death during which most retinal ganglion cells are eliminated (Stone et al., 1982; Williams et al., 1985). The mechanisms underlying this loss of cells, as well as the function of naturally occurring cell death, still require clarification. It is clear from the present study, however, that the cells comprising the exuberant projection from temporal retina to the contralateral LGNd are capable of making essentially normal, functional connections. Thus, it is unlikely that, during normal postnatal development, it is the inherent inability of these retinal ganglion cells to make functional connections that results in their eventual elimination. The competitive interactions in retinorecipient nuclei that mediate cell death in the developing cat retina (discussed in Leventhal et al., 1988a) are likely to occur between the axons of potentially viable cells.

\section{Relation to albinism}

The present results have implications for understanding the effects of albinism on the visual pathways. This study provides 

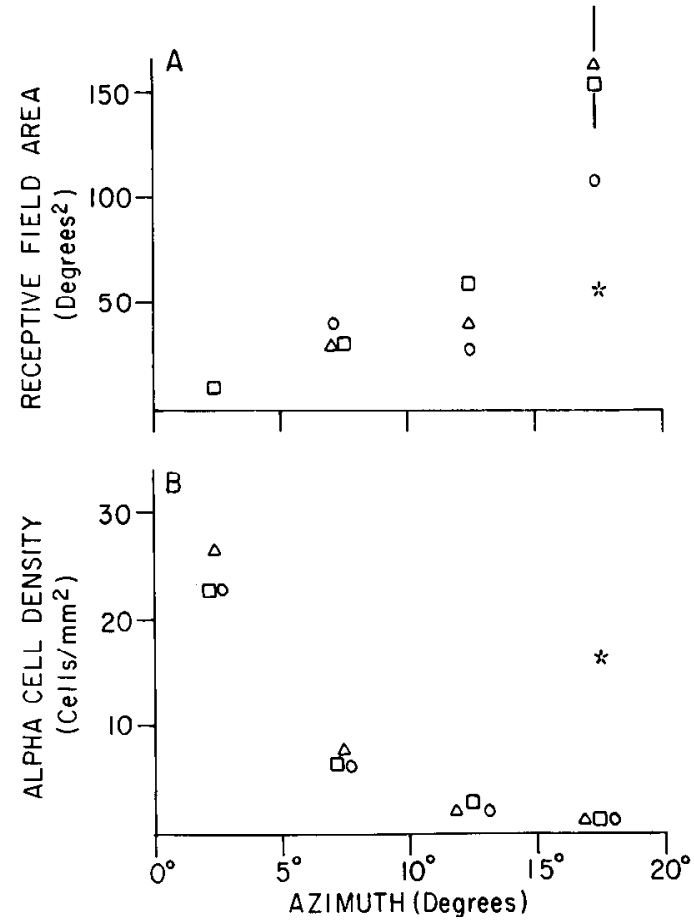

Figure 7. A, Receptive field area as a function of ipsilateral azimuth. Each symbol represents the mean receptive field area of the single units recorded in area 18 subserving regions about $10^{\circ}$ below the horizontal meridian; different symbols represent different animals. $B$, Density of $\alpha$ cells in the retinotopically corresponding regions of the contralateral temporal retinae of the same animals. The SE is indicated by the vertical bars; in most cases the SE was smaller than the size of the symbol. The mean receptive field area of single units in area $18,15^{\circ}-20^{\circ}$ from the vertical meridian in the normal cat at corresponding elevations in the contralateral hemifield is indicated by the asterisk in $A$. The asterisk in $B$ indicates the normal density of ipsilaterally projecting $\alpha$ cells in the topographically corresponding part of temporal retina. Note that receptive fields more than $15^{\circ}$ into the ipsilateral hemifield are significantly larger than their normal counterparts; the rapid size increase with ipsilateral azimuth corresponds to the rapid decrease with azimuth in the density of contralaterally projecting $\alpha$ cells in the peripheral temporal retina of the same animals.

evidence that the projections of ganglion cells in temporal retina, as well as the ipsilateral visual field representation in areas 17 and 18 of neonatally optic tract sectioned cats, bear a qualitative resemblance to what is observed in the Boston Siamese cat (Hubel and Wiesel, 1971; Shatz, 1977; Stone et al., 1978; Cooper and Pettigrew, 1979a; Cooper and Blasdel, 1980; Leventhal, 1982) or the albino heterozygote cat (Leventhal et al., 1985b). Thus, hypopigmentation is not necessary for an albino-like ipsilateral hemifield representation in visual cortex.

Rather, it appears that whenever a significant contingent of ganglion cells in temporal retina projects contralaterally to the LGNd in the adult, an albino-like representation of the visual field is found in the geniculocortical pathway. This suggests that the abnormal retinotopic organization of the LGNd and areas 17 and 18 commonly associated with the various forms of albinism (reviewed by Guillery, 1986) is secondary to the initial misrouting at the optic chiasm (Kliot and Shatz, 1985) in hypopigmented animals and is not a result of albinism per se.

\section{Relations between retinal and cortical topography}

There is one noteworthy difference betwcen OTX and hypopigmented cats. The contralaterally projecting ganglion cells in
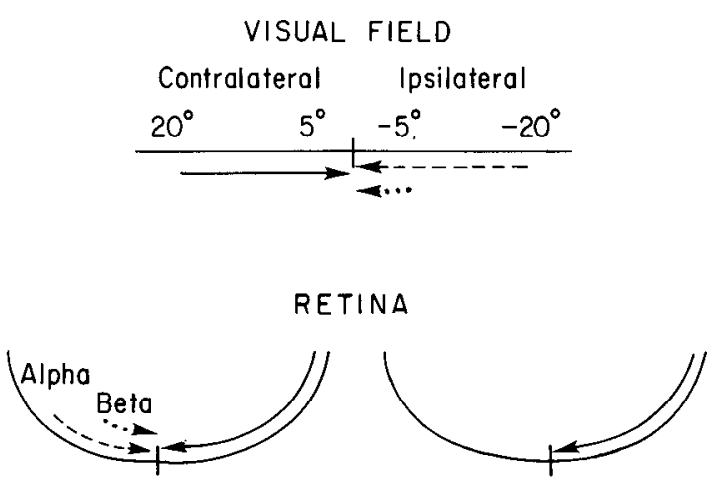

LATERAL GENICULATE NUCLEUS

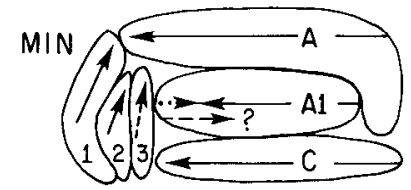

VISUAL CORTEX

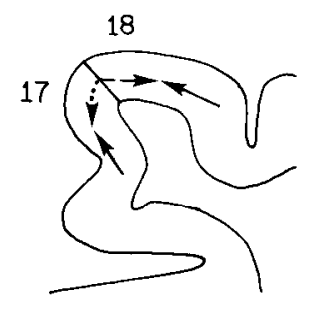

Figure 8. Schematic interpretation of the results. The visual field is represented at the top. The arrows indicate the regions subserved by $\alpha$ and $\beta$-type ganglion cells in different areas of the 2 retinae. The $\alpha$ cells (dashed arrow) extend further into the contralateral temporal retina than do $\beta$ cells (dotted arrow). Below the schematic retinae a typical coronal section of the LGNd and MIN is drawn. The arrows indicate the hypothesized retinal input and corresponding visual field representation. As in Siamese and albino cats, in OTX cats $\alpha$ and $\beta$ cells from the contralateral temporal retina project to the medial part of lamina Al (Leventhal, 1982). The extent of the ipsilateral visual field subserved by $\beta$ cells is less than that subserved by $\alpha$ cells. Consequently, LGNd $Y$ cells subserve more peripheral regions of the ipsilateral hemifield than do LGNd X cells. The $\alpha$ cells in contralateral temporal retina also project to lamina 3 of the MIN. As in normal cats, MIN Y cells represent a significant portion of the ipsilateral hemifield. At the bottom, a typical coronal section of the visual cortex is illustrated. The ipsilateral visual field representation is located at the border of areas 17 and 18. The ipsilateral hemifield representation is organized like that of a Boston Siamese or heterozygous albino cat. Less of the ipsilateral visual field is represented in area 17 than in area 18 . Since $\beta$ and $\alpha$ cells ultimately provide the major inputs to areas 17 and 18 , respectively, this difference is hypothesized to reflect the different distributions of contralaterally projecting $\beta$ and $\alpha$ cells in temporal retina.

the temporal retina of hypopigmented cats are surrounded by ipsilaterally projecting cells, but in OTX animals the contralaterally projecting ganglion cells in temporal retina have no neighbors.

In Siamese and heterozygous albino cats, afferents to regions of area 18 subserving the ipsilateral hemifield may come from the thalamus, other cortical areas, or via the corpus callosum. Since, in OTX cats the hemisphere ipsilateral to the section is 
devoid of ganglion cell input, area 18 in the intact hemisphere should receive no visual input via the corpus callosum. Furthermore, the present results indicate that regions of the ipsilateral hemifield more than $7^{\circ}$ from the vertical meridian are represented in area 18 but not in area 17; thus, cells in area 17 cannot provide visual input to regions of area 18 subserving the peripheral ipsilateral hemifield. Consequently, cells in area 18 subserving the peripheral ipsilateral hemifield are likely to be receiving visual input only from the thalamus. Since the inputs to area 18 are $Y$ cell dominated, this projection must ultimately originate from the misprojecting $\alpha(\mathrm{Y})$ cells in contralateral temporal retina. This situation provides an opportunity to investigate the relationship between cortical topography and receptive field properties and the morphology and distribution of retinal ganglion cells.

The present investigation indicated that the receptive fields of neurons in area 18 subserving the ipsilateral visual field were normally selective for orientation, direction, and velocity but were larger than normal. The morphology of the misprojecting $\alpha$ ganglion cells was visualized in the same animals studied physiologically, by injecting HRP into the ipsilateral visual field representation in the $\mathrm{LGNd}$. By relating the cortical receptive fields to retinal landmarks, it is possible to examine the distribution and morphology of the ganglion cells ultimately providing the inputs to a physiologically characterized region of the visual cortex (Fig. 6). In the OTX cats studied to date, we find that, for area 18 cells subserving the ipsilateral hemifield, receptive field size increases rapidly with azimuth; the increase in receptive field size and the magnitude of the response evoked by visual stimulation parallels the change in density and coverage of the $\alpha$ cell dendrites in the appropriate region of retina (Fig. 7). This suggests that the coverage of the retina by a single class of ganglion cells can determine receptive field size, response strength, and magnification factor in a well-defined visual cortical area.

\section{References}

Bowling, D. G., and C. R. Michael (1984) Terminal patterns of single, physiologically characterized optic tract fibers in the cat's lateral geniculate nucleus. J. Neurosci. 4: 198-216.

Cooper, M. L., and G. G. Blasdel (1980) Regional variation in the representation of the visual field in the visual cortex of the Siamese cat. J. Comp. Neurol. 193: 237-254.

Cooper, M. L., and J. D. Pettigrew (1979a) The decussation of the retinothalamic pathway in the cat, with a note on the major meridians of the cat's eye. J. Comp. Neurol. 187: 285-312.

Cooper, M. L., and J. D. Pettigrew (1979b) The retinothalamic pathways in Siamese cats. J. Comp. Neurol. 187: 313-348.

Creel, D. J. (1971) Visual system anomaly associated with albinism in the cat. Nature 231: 465-466.

Dow, B. M., and R. Dubner (1969) Visual receptive fields and responses to movement in an association area of cat cerebral cortex. J. Neurophysiol. 32: 773-784.

Dreher, B., A. G. Leventhal, and P. T. Hale (1980) Geniculate input to cat visual cortex: A comparison of area 19 with areas 17 and 18 . J. Neurophysiol. 44: 804-826.

Guillery, R. W. (1969) An abnormal retinogeniculate projection in Siamese cats. Brain Res. 14: 739-741.

Guillery, R. W. (1986) Neural abnormalities of albinos. Trends Neurosci. 9: $364-367$.

Guillery, R. W., and J. Kaas (1971) A study of normal and congenitally abnormal retinogeniculate projections in cats. J. Comp. Neurol. 143: 73-100.

Guillery, R. W., E. E. Geisert, E. H. Polley, and C. A. Mason (1980) An analysis of the retinal afferents to the cat's medial interlaminar nucleus and to its rostral thalamic extension, the "geniculate wing." J. Comp. Neurol. 194: 117-142.
Heath, C. J., and E. G. Jones (1972) The anatomical organization of the suprasylvian gyrus of the cat. Ergeb. Anat. Entwickl. 45: 4-64.

Hubel, D. H., and T. N. Wiesel (1965) Receptive fields and functional architecture in two nonstriate visual areas (18 and 19) of the cat. J. Neurophysiol. 28: 229-289.

Hubel, D. H., and T. N. Wiesel (1971) Aberrant visual projections in the Siamese cat. J. Physiol. (Lond.) 218: 33-62.

Illing, R. B., and H. Wässle (1981) The retinal projection to the thalamus in the cat: A quantitative investigation and a comparison with the retinotectal pathway. J. Comp. Neurol. 202: 265-285.

Jacobs, D. S., V. H. Perry, and M. J. Hawken (1984) The postnatal reduction of the uncrossed projection from the nasal retina in the cat. J. Neurosci. 4: 2425-2433.

Kaas, J. H., and R. W. Guillery (1973) The transfer of abnormal visual field representations from the dorsal lateral geniculate nucleus to the visual cortex in Siamese cats. Brain Res. 59: 61-95.

Kinston, W. J., M. A. Vadas, and P. O. Bishop (1969) Multiple projection of the visual field to the medial portion of the dorsal lateral geniculate nucleus and the adjacent nuclei of the thalamus of the cat. J. Comp. Neurol. 136: 295-316.

Kliot, M., and C. J. Shatz (1985) Abnormal development of the retinogeniculate projection in Siamese cats. J. Neurosci. 5: 2641-2653.

Lee, C., J. G. Malpeli, H. D. Schwark, and T. G. Weyand (1984) Cat mcdial interlaminar nucleus: Retinotopy, relation to tapetum and implications for scotopic vision. J. Neurophysiol. 52: 848-869.

Leventhal, A. G. (1982) Morphology and distribution of retinal ganglion cells projecting to different layers of the dorsal lateral geniculate nucleus in normal and Siamese cats. J. Neurosci. 2: 1024-1042.

Leventhal, A. G. (1983) Relationship between preferred orientation and receptive field position of neurons in cat striate cortex. J. Comp. Neurol. 220: 476-483.

Leventhal, A. G., and D. Creel (1985) Functional architecture of cortical areas 17 and 18 in tyrosine negative albino cats. J. Neurosci. 5: 795-807.

Leventhal, A. G., J. Keens, and I. Törk (1980) The afferent ganglion cells and cortical projections of the retinal recipient zone (RRZ) of the cat's "pulvinar complex." J. Comp. Neurol. 194: 535-554.

Leventhal, A. G., R. W. Rodieck, and B. Dreher (1985a) Central projections of cat retinal ganglion cells. J. Comp. Neurol. 237: 216226.

Leventhal, A. G., D. J. Vitek, and D. Creel (1985b) Abnormal visual pathways in normally pigmented cats that are heterozygous for albinism. Science 229: 1395-1397.

Leventhal, A. G., J. D. Schall, S. J. Ault, J. M. Provis, and D. J. Vitek (1988a) Class-specific cell death shapes the distribution and pattern of central projection of cat retinal ganglion cells. J. Neurosci. 8:20112027.

Leventhal, A. G., J. D. Schall, and S. J. Ault (1988b) Extrinsic determinants of retinal ganglion cell structure in the cat. J. Neurosci. 8: 2028-2038.

Maciewicz, R. J. (1974) Afferents to the lateral suprasylvian gyrus of the cat traced with horseradish peroxidase. Brain Res. 78: 139-143.

Mitzdorf, U., and W. Singer (1977) Laminar segregation of afferents of lateral geniculate nucleus of the cat: An analysis of current source density. J. Neurophysiol. 40: 1227-1244.

Niimi, K., H. Matsuoka, Y. Yamazaki, and H. Matsumoto (1981) Thalamic afferents to the visual cortex in the cat studied by retrograde axonal transport of horseradish peroxidase. Brain Behav. Evol. 18: 114-139.

Orban, G. A., H. Kennedy, and H. Maes (1981) Functional changes across the 17-18 border in the cat. Exp. Brain Res. 39: 177-186.

Palmer, L. A., A. C. Rosenquist, and R. J. Tusa (1978) The retinotopic organization of lateral suprasylvian visual areas in the cat. J. Comp. Neurol. 177: 237-256.

Raczkowski, D., and A. C. Rosenquist (1983) Connections of the multiple visual cortical areas with the lateral posterior-pulvinar complex and adjacent thalamic nuclei in the cat. J. Neurosci. 3: 19121942.

Rowe, M. H., and B. Dreher (1982) Retinal W-cell projections to the medial interlaminar nucleus in the cat: Implications for ganglion cell classification. J. Comp. Neurol. 204: 117-133.

Sanderson, K. (1971) The projection of the visual field to the lateral geniculate and medial interlaminar nuclei in the cat. J. Comp. Neurol. 143: 101-1 18

Schall, J. D., D. J. Vitek, and A. G. Leventhal (1986) Retinal constraints 
on orientation specificity in cat visual cortex. J. Neurosci. 6: 823836

Shatz, C. J. (1977) A comparison of visual pathways in Boston and Midwestern Siamese cats. J. Comp. Neurol. 171: 205-228.

Singer, W., F. Tretter, and M. Cynader (1975) Organization of cat striate cortex: A correlation of receptive field properties with afferent and efferent connections. J. Neurophysiol. 38: 1080-1098.

Spear, P. D., and T. P. Baumann (1975) Receptive field characteristics of single neurons in lateral suprasylvian visual area of the cat. J. Neurophysiol. 38: 1403-1420.

Stein, B. E., J. G. McHaffie, J. K. Harting, M. F. Heurta, and T. Hashikawa (1985) Transient tectogeniculate projections in neonatal kittens: An autoradiographic study. J. Comp. Neurol. 239: 402-412.

Stone, J., and B. Dreher (1973) Projection of X- and Y-cells of the cat's lateral geniculate nucleus to areas 17 and 18 of visual cortex. $J$. Neurophysiol. 36: 551-567.

Stone, J., J. E. Campion, and J. Leicester (1978) The nasotemporal division of the retina in the Siamese cat. J. Comp. Neurol. 180:783798.

Stone, J., D. H. Rapaport, R. W. Williams, and L. Chalupa (1982) Uniformity of cell distribution in the ganglion cell layer of prenatal cat retina: Implications for mechanisms of retinal development. Dev. Brain Res. 2: 231-242.
Sur, M., and S. M. Sherman (1982) Retinogeniculate terminations in cats: Morphological differences between $\mathrm{X}$ and $\mathrm{Y}$ cell axons. Science 218: 389-391.

Tong, L., R. E. Kalil, and P. D. Spear (1982) Thalamic projections to visual areas of the middle suprasylvian sulcus in the cat. J. Comp. Neurol. 212: 103-117.

Torrealba, F., G. D. Partlow, and R. W. Guillery (1981) Organization of the projection from the superior colliculus to the dorsal lateral geniculate nucleus of the cat. Neuroscience 6: 1341-1360.

Tretter, F., M. Cynader, and W. Singer (1975) Cat parastriatc cortcx: A primary or secondary visual area? J. Neurophysiol. 38: 1099-1113.

Tusa, R. J., A. C. Rosenquist, and L. A. Palmer (1979) Retinotopic organization of areas 18 and 19 in the cat. J. Comp. Neurol. 185 . $657-678$

Williams, R. W., M. J. Bastiani, B. Lia, and L. M. Chalupa (1985) Growth cones, dying axons and developmental fluctuations in the fiber population of the cat's optic nerve. J. Comp. Neurol. 246: 3269.

Wilson, M. E., and B. G. Cragg (1967) Projections from the lateral geniculate nucleus in the cat and monkey. J. Anat. 101: 677-692. 